\title{
Overt and Covert Postpartum Urinary Retention, Risk Factors and Complications
}

\author{
Zalina Nusee, N. Hikmah M. Noh, Aimi Rahayu A. Rashid, Hamizah Ismail and Hasliza Zakaria
}

\begin{abstract}
Background: The overall risk of postpartum urinary retention (PUR) is between $0.05 \%$ and $37 \%$. Being Asian increases the risk, while other factors include epidural analgesia, prolonged first and second stage of labour and previous history of PUR.

Subjects and Methods: This is a cohort study conducted at a tertiary hospital in Pahang State of Malaysia over one year duration. All postpartum women were included. The post void residual volume (PVRV) was measured after minimum 6 hours postpartum or when the subject complained of inability to pass urine. The PVRV of more than $150 \mathrm{ml}$ was considered as PUR. Data analysis was performed using SPSS version 20.

Results: Of 1000 included women, mean age was 28.44(5.68), parity of 2.0 and $75.8 \%$ had vaginal delivery. PUR was diagnosed in $42(4.2 \%)$ women, of whom $4(9.5 \%)$ were diagnosed with overt and $38(90.5 \%)$ had covert PUR. Parity and perineal tear were significantly associated with PUR. Second degree perineal tear (including episiotomy) were independent risk factors associated with PUR (adjusted OR 3.19, CI 1.23 - 8.30).

Conclusion: Incidence of PUR in our population is low compared with others. Second degree perineal tear (including episiotomy) is a risk factor for PUR. PUR screening is not needed in our population.
\end{abstract}

Index Terms - postpartum, urinary retention, post void residual volume, overt, covert.

\section{BACKGROUND}

Postpartum urinary retention (PUR) can be described as inability to pass urine at six hours postpartum. It is common clinically and proves to give significant morbidity to women [1]. Incidence reported in literature varies from $0.05 \%$ to $37 \%$ worldwide [2]. Physiologic changes of the bladder in pregnancy, epidural analgesia, instrumental deliveries, perineal trauma, vaginal birth after caesarean, and prolonged second stage of labour have all been associated with PUR (3-6). As well as that, being Asian ethnic origin increases the risk [1].

In 1997, a distinction between two types of PUR was made [3] and had since used widely in the literature. PUR is

Published on July 17, 2020

Zalina Nusee, International Islamic University Malaysia, Malaysia. (corresponding e-mail: drzalina@iium.edu.my)

N. Hikmah M. Noh, International Islamic University Malaysia, Malaysia.

(e-mail: nurulhikmah@iium.edu.my)

Aimi Rahayu A. Rashid, International Islamic University Malaysia, Malaysia.

(e-mail: aimirahayu ${ }^{@}$ gmail.com)

Hamizah Ismail, International Islamic University Malaysia, Malaysia. (e-mail: ihamizah@iium.edu.my).

Hasliza Zakaria, International Islamic University Malaysia, Malaysia. (e-mail: mamacome77@gmail.com). divided into two categories, overt and covert PUR. Women who fall into overt PUR category are those who are unable to micturate spontaneously within 6 hours postpartum or 6 hours after removal of indwelling catheter, with post void residual volume (PVRV) of more than $150 \mathrm{ml}$. This is deemed as symptomatic urinary retention. Covert PUR can only be detected by ultrasound or by catheterisation after spontaneous micturition, when the PVRV is more than $150 \mathrm{ml}$.

At present, there is no standard definition of PUR. Although the diagnosis of PUR relies on PVRV value, consensus on a standardized definition of PUR has not been reached. This could be due to the fact that there is no agreement on the cut-off value for PVRV which ranges from $50 \mathrm{ml}$ to $200 \mathrm{ml}$ and improper technique of the measurement using different bladder scans. However, PVRV value of 150 $\mathrm{ml}$ is widely used in literature [7] to detect PUR using bladder scan. The benefits of being non-invasive and readily available in most units make bladder scan an economic device to detect PUR [8].

Possibly, PUR screening for all postpartum women can be done as the resource is readily available and to limit future morbidities.

Complication of PUR is poorly reported in the literature. Some studies revealed that the problems resolved on long term follow up [9), others reported reversible and irreversible bladder damage which include detrusor hypotonia and instability [10], [11]. There is also reported small percentage of stress urinary incontinence [11].

This research was set to determine the acceptable value of PVRV in local population as well as the incidence of PUR, its risk factors and complications in a tertiary hospital in the state of Pahang.

\section{SubJects And Methods}

This is a prospective cohort study conducted over one year period. Data on the PVRV of women after delivery were collected. All consented women who delivered in this centre within study period were included in this study. Women who required prolonged catheterisation or those with serious medical or obstetrics issues were excluded. Data on potential risk factors were also collected.

The women were asked to inform the clinical staff of sensation to void. They were allowed to void and within 10 minutes after the first void, the PVRV was measured with a portable non-invasive abdominal ultrasound device (Bladder scan BVI 3000) for two readings. The use of Bladder scan BVI 3000 on postpartum women had been validated prior to this study [12]. The PVRV were measured by a trained research assistant in the proper use of the device. If the 
PVRV values were less than $150 \mathrm{ml}$, the women will be included in the control group. In women diagnosed with covert PUR (PVRV more than $150 \mathrm{ml}$ ), PVRV will be repeated in the ward until it was normal (less than $150 \mathrm{ml}$ ) or until day 4 post-delivery before discharged.

If women had no spontaneous micturition after 6 hours post-delivery or after removal of indwelling catheter, the bladder will be scanned. In women diagnosed with overt PUR, they will follow a set of management protocol similar to management of covert PUR (Fig. 1).

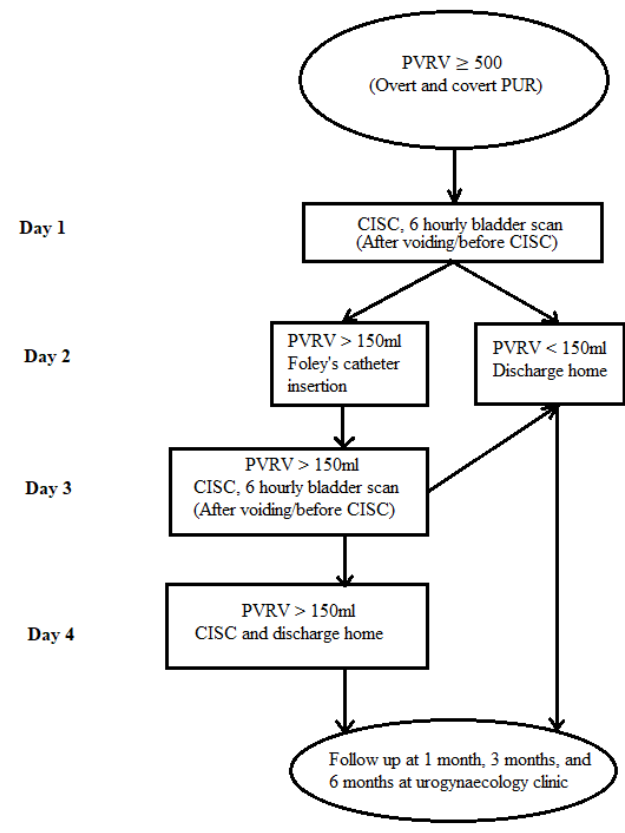

Fig. 1. PUR Management Protocol.

All groups were followed up at one, three and six months via phone call. Assessment of voiding dysfunction was done using "Validated Bahasa Malaysia Version" of Urogenital distress Inventory (UDI-6) questionnaire and Incontinence Impact Questionnaire (IIQ-7) [13]). Those with symptoms of voiding dysfunction will be reviewed in the outpatient urogynaecology clinic for confirmatory test. The method of this study is represented in Fig. 2.

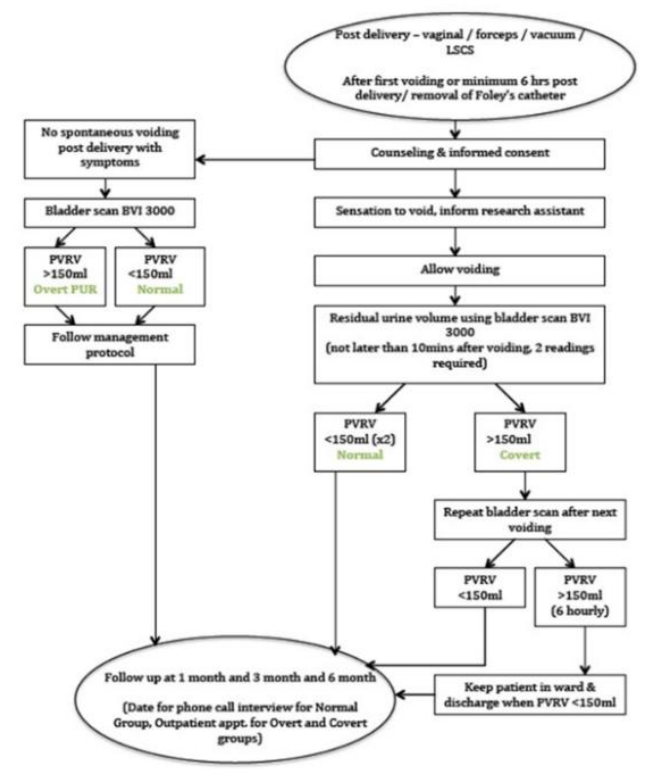

Fig. 2. Study Flow Chart.

\section{DATA ANALYSIS}

Statistical analysis was performed using SPSS version 20.0. The normal distribution was analysed by the Kolmogorov-Smirnov test. Continuous variables with normal distribution are presented as mean (standard deviation). Median (minimum-maximum) value was used where the data distribution is not normal. Quantitative variables are given as number (percentage). Statistical comparison was done using chi-square, Mann-Whitney U, and independent t-test accordingly. Analysis was performed for the PVRV values related to the 75th and 95th centiles with $\mathrm{p}$ value of $<0.05$ as statistically significant in a logistic regression model. Potential risk factors were reported as odd ratio with $95 \%$ confidence interval.

All of the study protocols were granted ethical approval by National Medical Research Registry prior to the start of the study.

\section{RESUlts}

The clinical data were recorded for 1000 women and 876 $(87.6 \%)$ completed the six-month follow up. The characteristics of the patients are shown in Table 1. The mean age of the women was 28.44 (SD 5.68) years old with the median age for PUR was 26 (24 - 30) years old, their median parity was 2 and $88.5 \%$ were of Malay origin.

Of 1000 included women, the incidence of PUR was only $42(4.2 \%)$, of whom $4(9.5 \%)$ were diagnosed with overt and $38(90.5 \%)$ had covert PUR.

TABLE 1: BASELINE CHARACTERISTICS

\begin{tabular}{|c|c|c|c|c|}
\hline Variable & $\begin{array}{c}\text { Total } \\
(\mathrm{n}=1000)\end{array}$ & $\begin{array}{c}\text { PUR } \\
(\mathrm{n}=42)\end{array}$ & $\begin{array}{l}\text { Normal } \\
(\mathrm{n}=958)\end{array}$ & $p$ value \\
\hline Age (years) & $28.44(5.7)^{\mathrm{a}}$ & $26(24-30)^{b}$ & $28(25-32)$ & 0.081 \\
\hline Parity ${ }^{\mathrm{b}}$ & $2(1-3)$ & $1(1-2)$ & $2(1-2)$ & 0.001 \\
\hline $\begin{array}{l}\text { Race }^{\mathrm{c}} \\
\text { Malay } \\
\text { Chinese } \\
\text { Indian } \\
\text { Others }\end{array}$ & $\begin{array}{c}885(88.5) \\
47(4.7) \\
9(0.9) \\
59(5.9)\end{array}$ & $\begin{array}{c}38(3.8) \\
3(0.3) \\
0(0) \\
1(0.1)\end{array}$ & $\begin{array}{c}847(84.7) \\
44(4.4) \\
9(0.9) \\
58(5.8)\end{array}$ & 0.380 \\
\hline $\begin{array}{l}\text { Mode of } \\
\text { Delivery } \\
\text { SVD } \\
\text { Vacuum } \\
\text { Forceps } \\
\text { LSCS }\end{array}$ & $\begin{array}{c}758(75.8) \\
39(3.9) \\
4(0.4) \\
199(19.9)\end{array}$ & $\begin{array}{c}31(3.1) \\
3(0.3) \\
2(0.2) \\
6(0.6)\end{array}$ & $\begin{array}{c}727(72.7) \\
36(3.6) \\
2(0.2) \\
193(19.3)\end{array}$ & 0.787 \\
\hline $\begin{array}{l}\text { Baby weight } \\
(\mathrm{kg})^{\mathrm{a}}\end{array}$ & $2.98(0.5)$ & $2.98(0.4)$ & $2.98(0.5)$ & 0.980 \\
\hline $\begin{array}{c}1^{\text {st }} \mathrm{SL} \\
\text { (minute) })^{\mathrm{b}}\end{array}$ & $\begin{array}{c}180(60- \\
300)\end{array}$ & $194(67-338)$ & $\begin{array}{c}180(60- \\
300)\end{array}$ & 0.892 \\
\hline $\begin{array}{c}2^{\text {nd }} \mathrm{SL} \\
\text { (minute) }^{\mathrm{b}}\end{array}$ & $7(5-15)$ & $8.5(2.5-3.0)$ & $7(5-15)$ & 0.484 \\
\hline
\end{tabular}

Abbreviations: PUR, postpartum urinary retention; SL, stage of labour. ${ }^{a}$ Mean (SD), by independent t-test.

${ }^{\mathrm{b}}$ Median (minimum-maximum), calculation by Mann Whitney-U test. ${ }^{\mathrm{c}} \mathrm{n}(\%)$, by Chi-Square test.

A logistic regression analysis (Table 3) was performed to see the association of risk factors to PUR. The logistic regression model was statistically significant, X2 (5) = $18.90, \mathrm{p}<0.015$. The analysis revealed women with second degree perineal tear and episiotomy were 3.19 times more likely to have PUR than other risk factors (CI 1.23 - 8.30). 
TABLE 2: RISK FACTORS FOR POSTPARTUM URINARY RETENTION

\begin{tabular}{lccc}
\hline \hline \multicolumn{1}{c}{ Risk factor } & $\begin{array}{c}\text { Normal } \\
(\%)\end{array}$ & $\begin{array}{c}\text { PUR } \\
(\%)\end{array}$ & $p$ value \\
\hline Perineal tear & & & \\
& 67.1 & 1.7 & $<0.001^{*}$ \\
Intact and 1st degree tear & 28.4 & 2.5 & \\
Episiotomy and 2nd tear & 0.3 & 0.0 & \\
3rd and 4th degree tear & & & \\
Analgesia & & & \\
& 27.0 & 0.5 & \\
No analgesia used & 49.6 & 3.1 & $0.724^{*}$ \\
Local analgesia & 4.2 & 0.3 & \\
General anaesthesia & 15.0 & 0.3 & \\
Spinal anaesthesia & & & \\
\hline lation by Linear Association). & & & \\
\end{tabular}

*(calculation by Linear Association)

TABLE 3: LOGISTIC REGRESSION ANALYSIS OF RISK FACTORS FOR POSTPARTUM URINARY RETENTION

\begin{tabular}{|c|c|c|c|c|}
\hline \multirow[t]{2}{*}{ Risk factor } & \multirow{2}{*}{$\begin{array}{l}\text { Adjusted } \\
\text { Odd Ratio }\end{array}$} & \multicolumn{2}{|c|}{$\begin{array}{c}95 \% \text { Confidence } \\
\text { Interval }\end{array}$} & \multirow[t]{2}{*}{$p$ value } \\
\hline & & Lower & Upper & \\
\hline \multicolumn{5}{|l|}{ Analgesia } \\
\hline Local & 1.65 & 0.50 & 5.41 & \multirow{3}{*}{$\begin{array}{l}0.41 \\
0.07 \\
0.86\end{array}$} \\
\hline $\mathrm{GA}^{*}$ & 3.96 & 0.89 & 17.57 & \\
\hline Spinal & 1.41 & 0.26 & 4.99 & \\
\hline Baby weight & 1.20 & 0.58 & 2.46 & 0.63 \\
\hline Age & 0.99 & 0.92 & 1.06 & 0.71 \\
\hline Parity & 1.07 & 0.79 & 1.43 & 0.66 \\
\hline Perineal tear*** & 3.19 & 1.23 & 8.90 & 0.02 \\
\hline
\end{tabular}

All women had their symptoms resolved before discharged with majority of hospital stay less than three days. A set of follow ups was done up to six months postpartum. Of 1000 women participated, 876 (87.6\%) women reported no recurrence of symptoms since discharged. There were also no symptoms of urinary tract infection, over active bladder $(\mathrm{OAB})$ or urinary incontinence reported. Unfortunately $124(12.4 \%)$ were lost to follow up either due to no contact number or the number not in used anymore.

Despite of having big sample size (1000), ROC curve to get normal PVRV value for local population filed to plot in view of very small number of PUR cases and result are not homogenous.

\section{DISCUSSION}

Women may feel difficult to express their problems concerning micturition postpartum, as many associate the symptoms with aftermath of a labour-intensive event. Far from being mystical, the effects of pregnancy and labour to the bladder are real. The hormonal changes during pregnancy [14] reduced the bladder tone and this increases the bladder capacity up to $1400 \mathrm{ml}$ starting from the third month of pregnancy. The pressure to feel the first sensation to void also increases compared to non-pregnant women. The increment may not be obvious due to pressure from enlarging uterus but it can cause difficulties in emptying out postpartum. Bladder sensation will return up to 10 hours post caesarean section under spinal analgesia and 6 hours after vaginal delivery with or without epidural analgesia.

PUR is a common condition to occur in the puerperium phase. Systematic review on adverse effects of PUR reported that we are still lacking in data to state that covert PUR is harmless [15]. Incomplete emptying of the bladder post-delivery may lead to urinary tract infections. Early diagnosis and intervention for postpartum urinary retention may help prevent bladder over-distension and associated irreversible bladder damage or prolonged bladder morbidity such as ureteric reflux, bilateral hydronephrosis, acute renal failure and long-term renal impairment.

This study involving 1000 women revealed the incidence of PUR to be $4.2 \%$, which is relatively low compared to similar research settings in the literature [9], [16]. Contrary to the research finding that being Asian increases the risk of PUR, our study shows the opposite [1].

From the logistic regression analysis, second degree perineal tear and episiotomy are risk factors associated with PUR in the population. The finding is consistent with other researches reporting relationship between perineal damage and PUR.

Although the exact pathophysiological reasoning behind these is still unclear, this positive relationship would seem to support certain hypotheses suggested. These include changes in the anatomy of the perineum and pelvic floor muscles [4], [17] and effects to the pudendal nerve conduction [18], [19]. The episiotomy would exert pain effects and disturbs the bladder function and sensitivity. Urethral and perineal edema may also increase the risk of urinary retention due to increased resistance to urine flow [3].

From our study, the incidence after caesarean section is lower compared to the study by Liang et al (24.1\%) [9]. Nerve damage from vaginal delivery has been associated with PUR. Pudendal nerve damage, as manifested by pudendal nerve terminal motor latency, is apparent after vaginal delivery [20], [21]. The pudendal nerve may have damaged directly and cause changes in the surrounding connective tissue, which would lead to further nerve damage. However, mode of delivery is not the risk factor statistically significant to cause PUR in our study.

Contrary to our study, duration of labour is found to be one of the risk factors for PUR in other literature [3], [9], [22]. Yip et al [3] hypothesized that the pelvic nerve plexuses in the pelvic soft tissue were affected by prolonged pressure of the fetus on the pelvic floor leading to tissue oedema or impairment of the detrusor muscle from neuropraxia which may lead to PUR. Labour duration of 700 minutes has been found to be a good predictor for PUR with receiver operating characteristic (ROC) of $0.63(95 \%$ CI, $0.57-0.70, \mathrm{p}<0.001)$ and OR of 1.003 (95\% CI, 1.001 1.004).

With regards to instrumental delivery as the contributory factor for PUR, our study did not reveal any significant association. This could be due to very small sample size of women undergone the procedure $(n=43,0.043 \%)$. However, study done by Liang et al with double sample size involving 2866 women delivered vaginally reported the contrary [22].

As the incidence of PUR is low in our population and the other studies reported resolutions of symptoms and no complications on women diagnosed with covert or overt PUR after 4 years, we concluded that PUR screening in our Asian population is not recommended. 
Although this was a large cohort study with 1000 women data on postpartum urinary retention after deliveries, there were some limitations that need to be discussed.

First, we screened the women for participation into the study. Those with long-term indwelling catheter requirement or with serious obstetrics and medical problems were excluded from the study. This is a clear-cut selection bias. However, we do not think that the postpartum urinary retention complications would be implicated by their preexisting problems to begin with. Therefore, the results from this study can be adapted and generalised for the population in our country.

Second, bladder scan as a hand-held, operator-dependent device was used to measure PVRV. We take every step within our capability to ensure that the PVRV measurements achieve conformity and standard of measurements reliability.Our research assistant involved in the study went through extensive training to be able to use the device correctly. This would minimise inaccuracy and off-standard data for analysis in the study.

\section{CONCLUSION}

The incidence of PUR in our population is low (4.2\%) compared to others. Second degree perineum tear and episiotomy are risk factors for PUR. Serial follow-ups for 6 months show resolution of symptoms in postpartum women without serious complications. Despite limitations of the study, we can safely conclude that routine screening for PUR in our population is not needed.

\section{ACKNOWLEDGMENT}

A special thanks to department of Obstetrics \& Gynecology, Hospital T. A. Afzan, Kuantan, Pahang for allowing us to conduct this study at their premise.

\section{FINANCIAL SUPPORT AND SPONSORSHIP}

This work was supported by Kulliyyah of medicine endowment fund.

\section{REFERENCES}

[1] Teo R, Punter J, Abrams K, Mayne C, Tincello D. Clinically overt postpartum urinary retention after vaginal delivery: a retrospective case-control study. Int Urogynecol J. 2007;18(5):521-24. doi 10.1007/s00192-006-0183-x.

[2] Mesut P, Mehmet BS, Cigdem P, Ozan D, Cetin K, Mehmet SB. Postpartum urinary retention: evaluation of risk factors. Turk $J$ Obstet Gynaecol. 2018; 15(2): 70-74. Doi 10.4274/tjod.43931.

[3] Yip SK, Brieger G, Hin LY, Chung T. Urinary retention in the postpartum period: the relationship between obstetric factors and the post-partum post-void residual bladder volume. Acta Obstet Gynecol Scand. 1997; 76(7):667-72.

[4] Iosif S, Ingemarsson I, Ulmsten U. Urodynamic studies in normal pregnancy and in puerperium. Am J Obstet Gynecol. 1980;137(6):696-700.

[5] Elliott RA, Castleden CM, Duffin HM. The effect of progesterone and oestrogen on rat detrusor muscle. Neurol Urodyn. 1992;11:3456.

[6] Groutz A, Levin I, Gold R, Pauzner D, Lessing JB, Gordon D. Protracted postpartum urinary retention: the importance of early diagnosis and timely intervention. Neurourol Urodyn. 2011;30(1):83-86. doi 10.1002/nau.20926.
[7] Bates CP, Bradley WE, Glen ES, Griffiths D, Melchior H, Rowan D, et al. Third Report on the Standardization of Terminology of Lower Urinary Tract Function Procedures related to the evaluation of micturition: pressure-flow relationships. Residual urine. Produced by the International Continence Society, February 1977. Br J Urol. 1980;52(5):348-50. doi 10.1111/j.1464-410X.1980.tb03058.x.

[8] Kermans G, Wyndaele JJ, Thiery M, De Sy W. Puerperal urinary retention. Acta Urol Belg 1986;54(4):376-85.

[9] Liang CC, Chang SD, Chang YL, Chen SH, Chueh HY, Cheng PJ. Postpartum urinary retention after cesarean delivery. Int J Gynecol Obstet. 2007; 99(3): 229-232. doi 10.1016/j.ijgo.2007.05.037.

[10] Amrita C, Kamini T. Persistent postpartum urinary retention following vaginal delivery:a rare complication in obstetric practice. Int J Reprod ContraceptObstet Gynaecol. 2013;2(3):475477. doi 10.5455/2320-1770.ijrcog20130951.

[11] Groutz A, Gordon D, Wolman I, Jaffa A, Kupferminc MJ, Lessing JB. Persistent postpartum urinary retention in contemporary obstetric practice: definition, prevalence and clinical implications. J Reprod Med. 2001;46(1):44-8.

[12] Zalina N, Norliza I, Razman MR, Hamizah I. Is portable threedimensional ultrasound a valid technique for measurement of postpartum urinary bladder volume? Taiwan J Obstet Gynaecol. 2013;53(1):12-6. doi: 10.1016/j.tjog.2013.01.028.

[13] Zalina N, Abdul Rahman J, Dalia F and Rozihan I.Tanslation and validation of bahasa Malaysia version of Urogenital distress Inventory(UDI-6) and Incontinece Impact Quality of life Questionaires (IIQ-7), a cross sectional study (2014). Malaysian Journal of Medical Sciences,23 (3 May-June), pp57-63, ISSN 1394-195X E-ISSN 2180-4303.

[14] Liang CC, Lin YH, Chen TC, Chang SD. How antepartum and postpartum acute urinary retention affects the function and structure of the rat bladder. Int Urogynecol J. 2014;25(8):1105-1113. doi: 10.1007/s00192-013-2320-7.

[15] Mulder FE, Hakvoort RA, Schoffelmeer MA, Limpens J, Van der Post JA, Roovers JP. Postpartum urinary retention: a systematic review of adverse effects and management. Int Urogynecol J. 2014;25(12):1605-1612. doi 10.1007/s00192-014-2418-6.

[16] Kekre AN, Vijayanand S, Dasgupta R, Kekre N. Postpartum urinary retention after vaginal delivery. Int J Gynecol Obstet. 2011;112(2) 112-115. doi 10.1016/j.ijgo.2010.08.014.

[17] Snooks SJ, Swash M, Mathers SE, Henry MM. Effect of vaginal delivery on the pelvic floor: a 5 years follow-up. $\mathrm{Br} J$ Surg. 1990;77(12):1358-1360.

[18] Lien KC, Morgan DM, DeLancey JO, Ashton-Miller JA. Pudendal nerve stretch during vaginal birth: a $3 \mathrm{D}$ computer simulation. Am J Obstet Gynecol. 2005;192(5):1669-1676.

[19] Sajadi KP, Lin DL, Steward JE, Balog B, Dissaranan C, Zaszczurynski $\mathrm{P}$, et al. Pudendal nerve stretch reduces external urethral sphincter activity in rats. J Urol. 2012;188(4):1389-1395

[20] Tetzschner T, Sørensen M, Lose G, Christiansen J. Pudendal nerve recovery after a noninstrumented vaginal delivery. Int Urogynecol J Pelvic Floor Dysfunct. 1996;7(2):102-4.

[21] Tetzschner T, Sørensen M, Lose G, Christiansen J. Pudendal nerve function during pregnancy and after delivery. Int Urogynecol $J$ Pelvic Floor Dysfunct. 1998;8(2):66-8.

[22] Ching-Chung L, Shuenn-Dhy C, Ling-Hong T, Ching-Chang H, Chao-Lun C, Po-Jen C. Postpartum urinary retention: assessment of contributing factors and long-term clinical impact. Aust $N$ Z J Obstet Gynaecol. 2002;42(4):365-8.

[23] Carley ME, Carley JM, Vasdev G, Lesnick TG, Webb MJ, Ramin $\mathrm{KD}$, et al. Factors that are associated with clinically overt postpartum urinary retention after vaginal delivery. Am J Obstet Gynecol. 2002;187(2):430-3.Groutz A, Gordon D, Wolman I, Jaffa A, Kupferminc MJ, Lessing JB. Persistent postpartum urinary retention in contemporary obstetric practice: definition, prevalence and clinical implications. J Reprod Med. 2001;46(1):44-8.

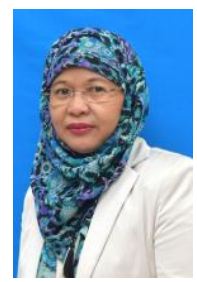

Dr Nusee was born in 1964 at Butterworth, Penang, Malaysia. Received medical degree from University Kebangsaan Malaysia (UKM), Bangi, Selangor in 1990. She obtained her second degree from the same university which specialized in Obstetrics \& Gynecology. She then underwent fellowship training in Urogynecology at Chang Gung Memorial Hospital, Taiwan in 2007

She had experienced working in various places locally as well oversea. Her places of working include: Muscat Private 
Hospital, sultanate of Oman, Royal Hospital, Sultanate of Oman, Hamad Hospital, Doha, Kuantan Medical Centre, Malaysia and Hospital T Ampuan Afzan, Kuantan, Pahang, Malaysia. Currently she is an associate professor serving International Islamic University Malaysia. 